\title{
A systematic review of flap fixation techniques in reducing seroma formation and its sequelae after mastectomy
}

Citation for published version (APA):

van Bastelaar, J., van Roozendaal, L., Granzier, R., Beets, G., \& Vissers, Y. (2018). A systematic review of flap fixation techniques in reducing seroma formation and its sequelae after mastectomy. Breast Cancer Research and Treatment, 167(2), 409-416. https://doi.org/10.1007/s10549-017-4540-x

Document status and date:

Published: 01/01/2018

DOI:

10.1007/s10549-017-4540-x

Document Version:

Publisher's PDF, also known as Version of record

Document license:

Taverne

Please check the document version of this publication:

- A submitted manuscript is the version of the article upon submission and before peer-review. There can be important differences between the submitted version and the official published version of record.

People interested in the research are advised to contact the author for the final version of the publication, or visit the DOI to the publisher's website.

- The final author version and the galley proof are versions of the publication after peer review.

- The final published version features the final layout of the paper including the volume, issue and page numbers.

Link to publication

\footnotetext{
General rights rights.

- You may freely distribute the URL identifying the publication in the public portal. please follow below link for the End User Agreement:

www.umlib.nl/taverne-license

Take down policy

If you believe that this document breaches copyright please contact us at:

repository@maastrichtuniversity.nl

providing details and we will investigate your claim.
}

Copyright and moral rights for the publications made accessible in the public portal are retained by the authors and/or other copyright owners and it is a condition of accessing publications that users recognise and abide by the legal requirements associated with these

- Users may download and print one copy of any publication from the public portal for the purpose of private study or research.

- You may not further distribute the material or use it for any profit-making activity or commercial gain

If the publication is distributed under the terms of Article $25 \mathrm{fa}$ of the Dutch Copyright Act, indicated by the "Taverne" license above, 


\title{
A systematic review of flap fixation techniques in reducing seroma formation and its sequelae after mastectomy
}

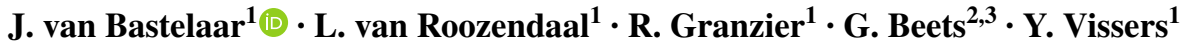

Received: 23 September 2017 / Accepted: 11 October 2017 / Published online: 16 October 2017

(C) Springer Science+Business Media, LLC 2017

\begin{abstract}
Background Seroma formation is a common complication after mastectomy. This review aims to elucidate which surgical techniques are most effective in reducing the dead space and therefore seroma formation in patients undergoing mastectomy.

Methods A literature search was performed to identify clinical studies comparing any form of flap fixation to conventional closure technique in patients undergoing mastectomy with or without axillary clearance. Studies were eligible for inclusion if outcome was described in terms of seroma formation and/or complications of seroma formation. Studies on animal research or breast reconstruction with tissue expanders or flap harvesting (latissimus dorsi) were excluded.

Results A total of nine articles were eligible for inclusion. Five were retrospective studies and four were prospective. Retrospective and prospective studies have demonstrated the higher incidence of seroma formation in patients not undergoing mechanical flap fixation. The incidence of seroma-related complications in these studies vary. Four out of the nine studies demonstrate that patients undergoing flap fixation, need significantly fewer seroma aspirations. There are very few studies on the use of tissue glues preventing seroma formation.
\end{abstract}

J. van Bastelaar

j.vanbastelaar@zuyderland.nl

1 Department of Surgery, Zuyderland Medical Center, Sittard-Geleen, The Netherlands

2 Department of Surgery, Netherlands Cancer Institute, Amsterdam, The Netherlands

3 GROW School for Oncology and Developmental Biology, University of Maastricht, Maastricht, The Netherlands
Conclusion The scientific body of evidence favoring flap fixation after mastectomy is convincing. Mechanical flap fixation seems to reduce seroma formation and seroma aspiration after mastectomy. There are, however, no well-powered randomized controlled trials evaluating all aspects of seroma formation and its sequelae. Further research should elucidate whether flap fixation using sutures or tissue glue is superior.

Keywords Mastectomy $\cdot$ Seroma formation $\cdot$ Seroma aspiration · Flap fixation

\section{Introduction}

Seroma formation after mastectomy is defined as a collection of serous fluid containing blood plasma and/or lymph fluid under the skin flaps or in the axilla. The reported incidence of seroma varies greatly, ranging from $3 \%$ to more than $90 \%$ [1-3]. Seroma formation should be regarded as a complication following mastectomy, although some consider it to be an unavoidable surgical nuisance. Seroma formation can lead to patient discomfort, repeated seroma aspirations with the risk of infection, prolonged hospital stay, delayed wound healing, skin flap necrosis, delay in commencing adjuvant therapies, and higher surgical expenditures [4-6].

The pathophysiology of seroma formation has been extensively analyzed. The extent of axillary lymph node involvement, type and extent of breast surgery, and the use of electrocautery have all been related to seroma formation [7-10]. In recent years, there have been many publications on effective techniques to prevent seroma formation. These techniques all appear to have one common denominator: reduction of the dead space [11]. Various methods have been described to reduce the dead space after mastectomy: closed suction drainage, quilting of 
the skin flaps, and application of adhesive tissue glues [12-16]. This review aims to elucidate which surgical flap fixation techniques are most effective in reducing the dead space and therefore seroma formation and its sequelae in patients undergoing mastectomy.

\section{Materials and methods}

This systematic review was performed using the recommendations of the systematic reviews and meta-analyses (PRISMA) guideline [17]. A review of the literature was performed to identify consecutive studies on flap fixation in breast cancer patients undergoing mastectomy. Medline, Cochrane Library, and Embase were searched for the following MESH terms: 'mastectomy' and 'seroma.' In order to retrieve all potentially eligible articles, the following search terms were added: 'quilting,' 'flap anchoring,' and 'flap fixation.' Cross-referencing of the bibliography of selected articles was performed.

We limited this review to studies with a retrospective or prospective nature, reporting on patients undergoing mastectomy with or without axillary clearance. Articles were selected that included patients undergoing any form of flap fixation (reducing the dead space between the skin flaps and pectoral muscle) that was compared to a conventional closure technique. If outcome was described in terms of seroma formation and/or complications of seroma formation, studies were eligible for inclusion. Articles older than 20 years and articles not written in English were excluded. Furthermore, all studies involving animal research or cases involving patients undergoing direct breast reconstruction with tissue expanders or flap harvesting (lattisimus dorsi) were excluded from this review.

Search and selection of articles was independently performed by two authors (RG, LvR). First selection was based on title and abstract screening and final selection of eligible articles was made after article reading. In case of inconsistency in selection, a third author ( JvB) was involved to make the final decision.

Assessment of the clinical and methodological quality of the eligible studies was undertaken. In case of a randomized controlled trial, we assessed the generation of random sequence, concealment of allocation, and blinding of allocation (Cochrane Handbook for Systematic Reviews of Interventions Version 5.0.2. http://www.cochranehandbook.org). A descriptive analysis was performed in the analysis of seroma-related complications, as it was not possible to perform a meta-analysis due to the high level of heterogeneity of the interventions.

\section{Results}

The search resulted in 37 articles. Fifteen articles were excluded based on title and abstract. Final selection after article reading resulted in nine articles that met the predefined inclusion criteria (Fig. 1). Of these studies, five were retrospective in nature and four studies were prospective (Tables 1, 2). Cross-referencing did not provide additional eligible articles. Table 3 represents a listing of the various studies in chronological order with specific seroma complications per study.

Almond et al. [6] performed a prospective study in which 135 patients undergoing mastectomy and/or axillary clearance were allocated to either a control group with suction drain placement or flap fixation. Flap fixation was achieved by using multiple rows of interrupted Vicryl sutures; all sutures were buried and placed $2.5 \mathrm{~cm}$ apart. Drains were removed when draining less than $50 \mathrm{ml}$ of serous fluid per day. There was no difference in seroma formation between the drain group (59\%) and the flap fixation group (49\%). Median length of stay was significantly longer in the group undergoing suction drain placement (2.67 vs. 1.88 days) in the flap fixation group $(p<0.0001)$. The authors state that when looking at costs, flap fixation seams to lead to considerable overall financial savings [6].

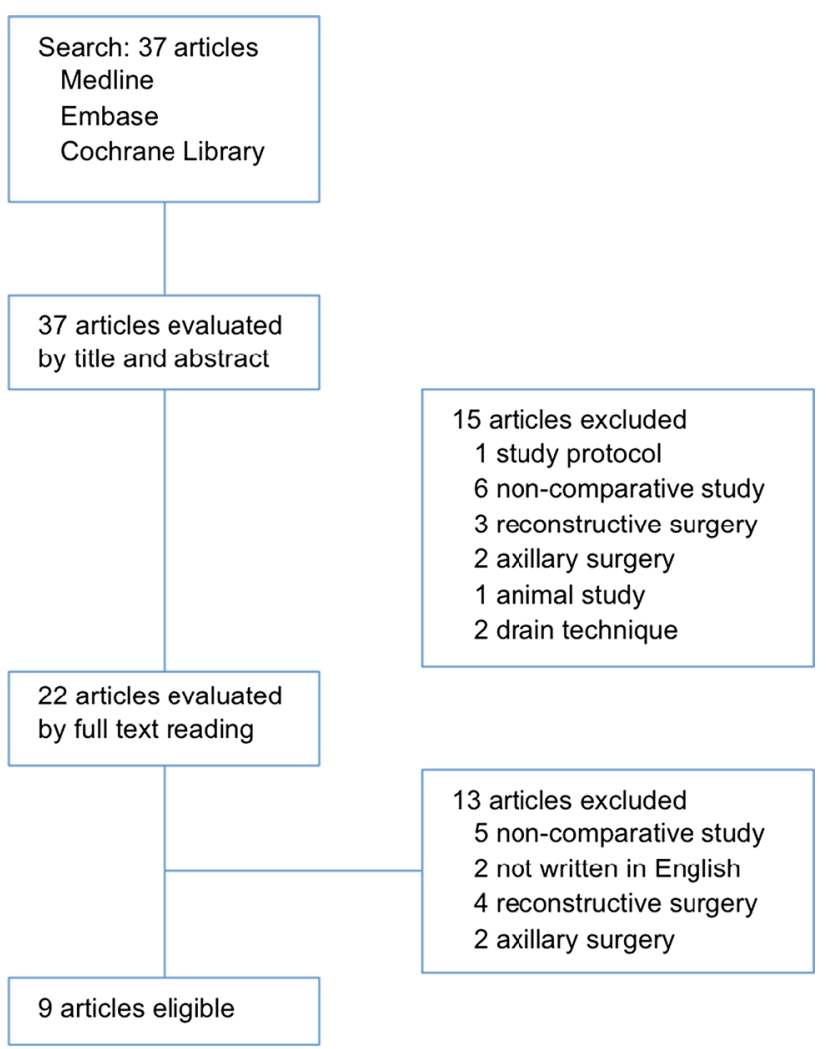

Fig. 1 Flowchart of the selection of eligible articles 
Table 1 Retrospective studies comparing the clinical presence of seroma in patients undergoing flap fixation

\begin{tabular}{lllllc}
\hline Authors & Year & Procedure performed & $N$ & Reference & $p$ value \\
\hline Ten Wolde & 2014 & Flap fixation using sutures & 176 & {$[19]$} & $\mathbf{0 . 0 0 0}^{*}$ \\
Ouldamer & 2015 & Quilting using running sutures & 119 & {$[20]$} & $<\mathbf{0 . 0 0 1}^{*}$ \\
Van Bastelaar & 2016 & Flap fixation using sutures & 180 & {$[23]$} & $\mathbf{0 . 0 0 2}^{*}$ \\
Eichler & 2016 & Flap fixation using TissuGlu & & \\
Van Bastelaar & 2017 & Flap fixation using ARTISS & 205 & {$[24]$} & 0.06 \\
\end{tabular}

Bold values indicate significance at $p<0.05$

\begin{tabular}{lllrlc}
\hline Authors & Year & Procedure performed & $N$ & Reference & $p$ value \\
\hline Almond & 2010 & Flap fixation using sutures & 135 & {$[6]$} & 0.22 \\
Sakkary & 2012 & Flap fixation using sutures & 40 & {$[18]$} & $\mathbf{0 . 0 2 8 *}$ \\
Khater & 2015 & Quilting using running sutures & 120 & {$[21]$} & $<\mathbf{0 . 0 0 1}^{*}$ \\
Mazouni & 2015 & Flap fixation using sutures & 87 & {$[22]$} & $\mathbf{0 . 0 3 *}$ \\
\hline
\end{tabular}

Bold values indicate significance at $p<0.05$
Table 2 Prospective studies comparing the clinical presence of seroma in patients undergoing flap fixation suction drain or wound closure with quilting sutures. Quilting consisted of several evenly spaced $(<2 \mathrm{~cm})$ parallel rows of running Vicryl 0/0 sutures to close the dead space. Only patients undergoing modified radical mastectomy in the quilting group received a suction drain. There was a significant reduction of clinically evident seromas in the quilting group (17\% vs. $51.7 \%, p<0.001)$. The length of hospital stay was significantly shorter in the quilting group (4.24 days vs. 5.43 days, $p<0.0001$ ). Self-assessment (cosmesis) was significantly better in the quilting suture group: good and excellent versus poor and acceptable in the group undergoing conventional wound closure $(p=0.003)$. There were no significant differences in postoperative hematomas or surgical site infections [20].

A prospective randomized controlled trial by Khater et al. was published in 2015. Patients undergoing modified radical mastectomy ( $n=120)$ were randomized into one of two groups. In the first group, quilting was applied to the skin flaps using a Vicryl 2/0 suture. In the second group, mastectomy was performed in the same fashion without quilting of the skin flaps. All patients received a 18-French tube drain. Seroma was present in $20 \%$ of the patients that underwent quilting and in $78.3 \%$ of the patients in the drain-only group $(p<0.001)$. There was a significantly higher number of aspirations in the drain-only group (4.7 vs. $2.1, p<0.001$ ). Postoperative hematoma formation and skin flap necrosis were indifferent. Patients in the intervention group had a significantly longer operative time in comparison to the drain-only group (127 min vs. $105 \mathrm{~min}, p<0.001)$. Patients and doctors were not blinded regarding the application of flap fixation [21].

Mazouni et al. [22] conducted a prospective monocentric observational non-randomized study. They included 82 patients undergoing mastectomy with or without axillary either underwent conventional wound closure with a closed 


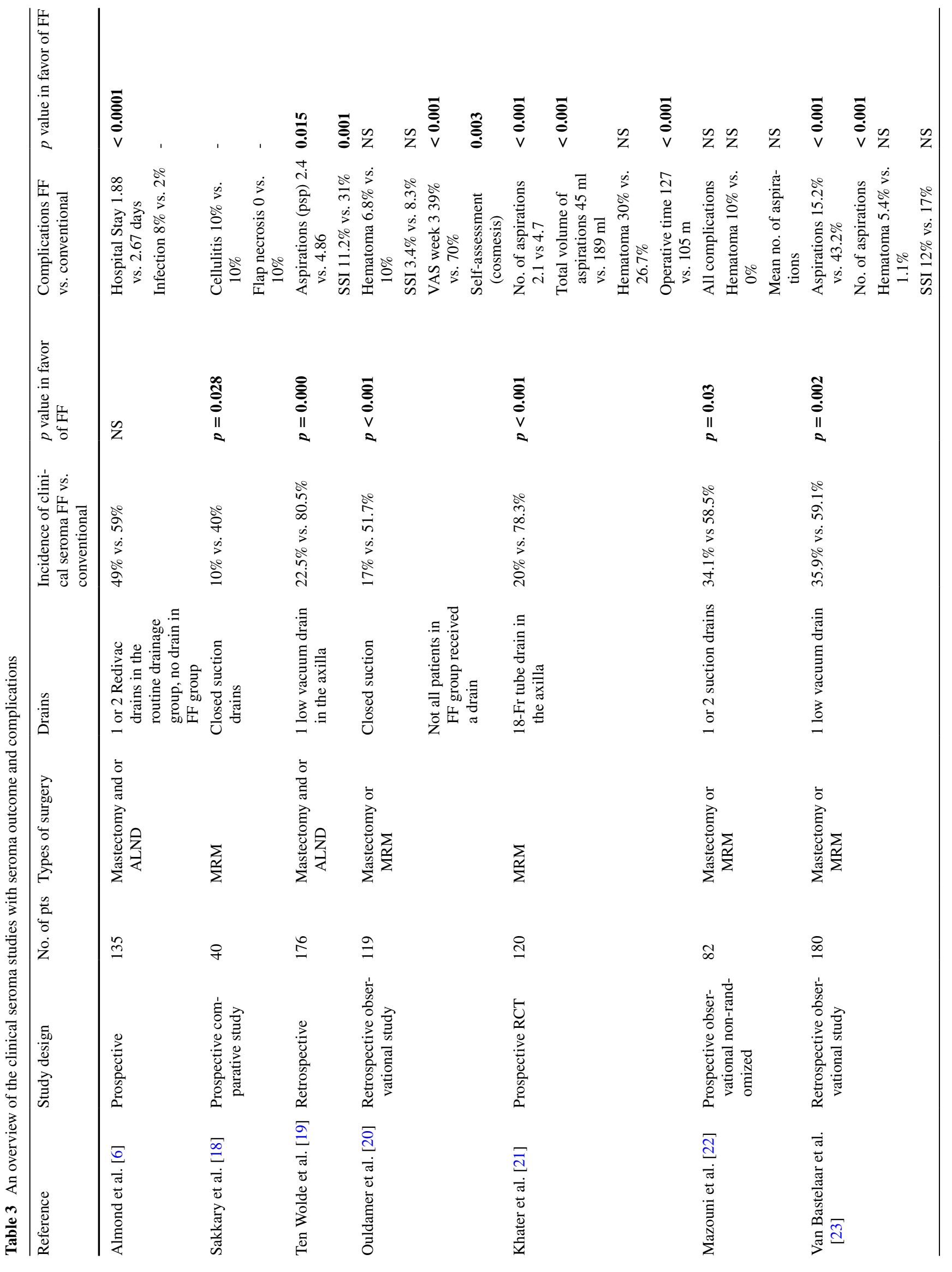


staging. Either flap fixation using 5-6 interrupted Vicryl $2 / 0$ sutures was applied or no closure of the dead space. All patients received 1 or 2 suction drains. The incidence of clinical significant seroma was lower in the flap fixation group (34.1\% vs. $58.8 \%, p=0.03)$. There were, however, no significant differences in seroma-related complications between both the groups [22].

The study done by Van Bastelaar et al. in 2016 was a retrospective multicenter study conducted in patients undergoing mastectomy with or without axillary clearance. Patients either underwent flap fixation with interrupted Vicryl 3/0 sutures at 3-cm intervals or wound closure without flap fixation. All patients received a low vacuum drain. A total of 180 patients were included. There were significantly fewer patients with clinically evident seroma formation in the flap fixation group ( $35.9 \%$ vs. $59.1 \%, p=0.002)$. Significantly more patients underwent seroma aspiration in the historical control group ( $15.2 \%$ vs. $43.2 \%, p<0.001)$. The number of aspirations per patient were higher in the historical control group $(p<0.001)$. The occurrence of hematoma or surgical site infections was not significantly different [23].

Only two studies have reported on flap fixation using tissue glue.

Eichler et al. [24] conducted a retrospective study in which 205 patients undergoing mastectomy with or without axillary clearance were analyzed. There were 173 patients in the control group and 32 in the TissuGlu ${ }^{\circledR}$ group. In the intervention group, TissuGlu ${ }^{\circledR}$ was applied to achieve equally spaced droplet placement on the pectoral muscle. Following wound closure, wound compression was performed with an elastic bandage for the first $24 \mathrm{~h}$. All patients received 1 or 2 non-suction drains. Seroma occurred in $27.6 \%$ of the patients in the intervention group, while only $15.6 \%$ of the patients in the control group developed seroma $(p=0.06)$. There was significantly more post-surgical hematoma formation in the control group ( $16.8 \%$ vs. $3.2 \%, p=0.045)$. There were no further differences in adverse events (revision, infection) [24].

Van Bastelaar et al. [23] published a retrospective observational cohort study in 2017. In this study, 138 patients undergoing mastectomy with or without axillary clearance were included. There were three groups: flap fixation with sutures (as published in 2016), flap fixation using ARTISS $^{\circledR}$ tissue glue, and a drain-only group. The method of wound closure depended on the period in which patients underwent mastectomy. As these authors had previously published the results of the group with flap fixation using sutures, these patients were excluded from this review. All patients received low vacuum drainage. There was no significant differences in clinical seroma formation (flap fixation using ARTISS $^{\circledR} 50 \%$ vs the drain-only group $59 \%, p=0.30$ ). There were, however, significantly more patients undergoing seroma aspiration in the drain-only group (43\%) compared to 
the ARTISS $^{\circledR}$ group $(14 \%)(p<0.001)$. Other complications showed no significant differences [25].

Figure 2 is a forest plot representing the effect of flap fixation on clinically evident seroma formation. All 9 reported studies have been included. There is a significant improvement in clinically evident seroma formation when flap fixation is applied.

\section{Discussion}

Effectively, few articles have been published on the occurrence of seroma and its sequelae in patients undergoing flap fixation after mastectomy with or without axillary clearance. We identified five retrospective studies and four prospective studies. Techniques used for flap fixation in these studies are quilting or tissue glue.

The most frequently employed technique for prevention of seroma is closed suction drainage. In the last decades, there have been many publications on the use of suction drainage to prevent seroma formation [26-31]. Until now, closed suction drainage is regarded as standard treatment and should be seen as the gold standard in reducing the dead space. For this reason, all studies investigating the effect of mechanical flap fixation should compare their results to patients being treated with a drain policy.

In the study conducted by Almond et al. [6], performing flap fixation was determined by their assigned consultant, possibly leading to some form of selection bias. One consultant always used drains while the other consultant applied flap fixation without drain placement. When evaluating the effectiveness of a new treatment strategy, it is difficult to assess the result of instituted treatment if more than one variable has been changed [(1) applying flap fixation and (2) omitting drains in the same group]. There were also patients that only underwent axillary clearance in this study (52/135).
Ideally, we would have excluded these patients from the review. Moreover, patients in the flap fixation group did not receive drains. Median length of stay was longer for patients with a drain. Flap fixation seemed to lead to overall financial savings. Institution of home nursing for most patients nowadays makes this outcome less relevant. In Sakkary's study, there was a significantly higher occurrence of seroma in the drain-only group and no significant differences in seromarelated complications. Drains were left in situ for a long period (median 13.4 days) in the drain-only group. These days, drains are often removed irrespective of drain output and are left in situ for a maximum of 5-7 days. Ten Wolde conducted a study in patients undergoing mastectomy and/ or axillary clearance. Twenty-seven patients (15.3\%) with only axillary clearance were included. There were significantly more patients in the non-quilting group undergoing axillary dissection $(60.9 \%$ vs. $38.2 \%, p=0.002)$. This could definitely be related to the higher incidence of seroma and higher incidence of seroma aspirations and surgical site infections in this study.

In the publications by Ouldamer et al., it was not clear if all participants received a drain. The authors were contacted and patients in the quilting group without axillary clearance did not receive a drain. Patients' self-assessment of cosmesis seemed significantly better in the quilting group. One should remember that patients were not blinded and this should be seen as a significant bias in this study. The study performed by Khater et al. is the only study that could be considered a randomized controlled trial. Only patients undergoing modified radical mastectomy were included in this study. This study showed very clear differences in seroma formation and seroma aspirations in favor of flap fixation. In the study performed by Mazouni et al., the main limitation was the relatively low number of patients. No conclusions could be drawn on the incidence of seroma and the mean number of seroma aspirations in both groups. Both studies published by van Bastelaar et al. are retrospective in nature, and as

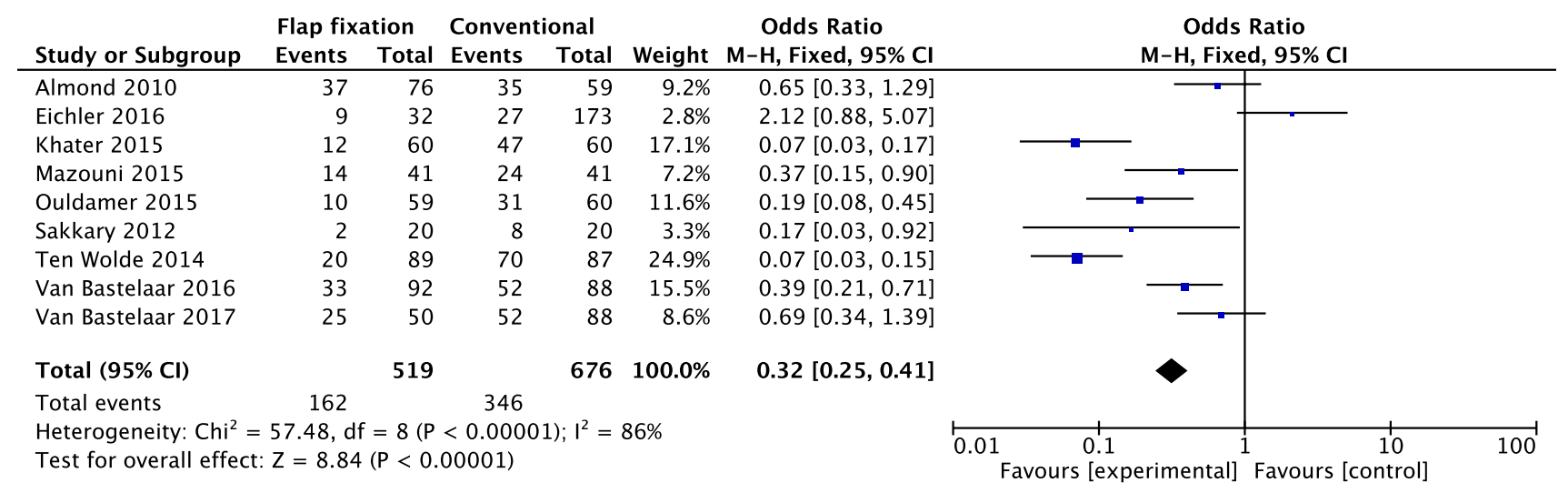

Fig. 2 Forest plot for seroma formation. $M-H$ Mantel-Haenszel, $C I$ confidence interval 
patients were sequentially assigned to a group determining whether flap fixation was performed, there might be a raised awareness for seroma as the study progressed. This could be considered a bias. In the retrospective study published by Eichler, 205 patients were included, but only 32 patients were in the intervention group. Seroma formation was nearly significantly higher in the intervention (TissuGlu ${ }^{\circledR}$ ) group. The intervention group was, however, also more frequently monitored than the control group, therefore possibly leading to an underestimation of seroma in the control group. Higher numbers of patients in the intervention group might have revealed significant differences.

The scientific body of evidence for flap fixation after mastectomy seems convincing. Retrospective and prospective studies have demonstrated the higher incidence of seroma formation in patients not undergoing mechanical flap fixation. There are, however, no well-powered randomized controlled trials evaluating all aspects of seroma formation and its sequelae. The incidence of seroma-related complications in the studies reviewed varies. Four out of the nine studies demonstrate that patients undergoing flap fixation, need significantly fewer seroma aspirations. There are very few studies on the use of tissue glues preventing seroma formation. Flap fixation using Fibrin Glue (Tisseel) was evaluated in a Cochrane review in 2013 [32]. The authors found no influence on the incidence of postoperative seroma formation, the mean volume of seroma, wound infections, complications, and the length of hospital stay after mastectomy for breast cancer [32]. However, due to a broad heterogeneity of included articles in the Cochrane review (e.g., population, type of surgery), it is difficult to extrapolate these results to our group of patients. More studies need to be conducted to evaluate the effect of tissue glues in relation to flap fixation using sutures.

One should take care when interpreting the results of the forest plot in Fig. 2 due to the large heterogeneity $\left(I^{2}=86 \%\right)$. Due to the diversity in reporting of seroma-related complications (aspiration, hematoma formation, and SSI's), forest plots could not be performed.

Van Bastelaar et al. have started a prospective randomized controlled trial (seroma reduction after mastectomy-trial, SAM TRIAL) to evaluate the effects of flap fixation (no flap fixation vs. flap fixation using sutures vs. flap fixation using tissue glue), including seroma formation and its sequelae, as well as long-term outcome measures, such as cosmesis, shoulder function, patient satisfaction, quality of life, and cost effectiveness.

\section{Conclusion}

The scientific body of evidence favoring flap fixation after mastectomy is convincing. Mechanical flap fixation seems to reduce seroma formation and seroma aspiration after mastectomy with or without axillary clearance. There are, however, no well-powered randomized controlled trials evaluating all aspects of seroma formation and its sequelae. Further research should elucidate whether flap fixation using sutures or tissue glue is superior.

\section{Compliance with ethical standards}

Conflict of interest All authors declare that they have no conflict of interest and that no funding was involved.

\section{References}

1. Carless PA et al (2006) Systematic review and meta-analysis of the use of fibrin sealant to prevent seroma formation after breast cancer surgery. Br J Surg 93(7):810-819

2. Kumar $S$ et al (1995) Post-mastectomy seroma: a new look into the aetiology of an old problem. J R Coll Surg Edinb 40:292-294

3. Woodworth PA et al (2000) Seroma formation after breast cancer surgery; incidence and predicting factors. Am Surg 66(5):444-450

4. Tadych K et al (1987) Postmastectomy seromas and wound drainage. Surg Gynecol Obstet 165(6):483-487

5. Kumar S et al (1995) Post-mastectomy seroma: a new look into the aetiology of an old problem. J R Coll Surg Edinb 40:292-294

6. Almond LM et al (2010) Flap anchoring following primary breast cancer surgery facilitates early hospital discharge and reduces costs. Breast Care 5(2):97-101

7. Petrek J et al (1990) Axillary lymphadenectomy: a prospective, randomized trial of 13 factors influencing drainage, including early or delayed arm mobilization. Arch Surg 125:378-382

8. Hashemi E et al (2004) Seroma formation after surgery for breast cancer. World J Surg Oncol 9(2):44

9. Gonzalez EA et al (2003) Seroma formation following breast cancer surgery. Breast J 9(5):385-388

10. Porter KA et al (1998) Electrocautery as a factor in seroma formation following mastectomy. Am J Surg 176:8-11

11. Van Bemmel AJ et al (2011) Prevention of seroma formation after axillary dissection in breast cancer: a systematic review. Eur J Surg Oncol 37(10):829-835

12. Pogson CJ et al (2003) Seroma following breast cancer surgery. Eur J Surg Oncol 29:711-717

13. Agrawal A et al (2006) Concepts of seroma formation and prevention in breast cancer surgery. ANZ J Surg 76:1088-1095

14. Turner EJH et al (2014) Techniques in the prevention and management of seromas after breast surgery. Future Oncol 10(6):1049-1063

15. Kuroi K et al (2006) Effect of mechanical closure of dead space on seroma formation after breast surgery. Breast Cancer 13:260-265

16. Srivastava $\mathrm{V}$ et al (2012) Seroma formation after breast cancer surgery: what we have learned in the last two decades. J Breast Cancer 15(4):373-380

17. Liberati A et al (2009) The PRISMA statement for reporting systematic reviews and meta-analyses of studies that evaluate health care interventions: explanation and elaboration. PLos Med 6(7):e1000100

18. Sakkary MA et al (2012) The value of mastectomy flap fixation in reducing fluid drainage and seroma formation in breast cancer patients. World J Surg Oncol 10:8

19. Ten Wolde B et al (2014) Quilting prevents seroma formation following breast cancer surgery: closing the dead space by quilting 
prevents seroma following axillary lymph node dissection and mastectomy. Ann Surg Oncol 21:802-807

20. Ouldamer L et al (2015) Quilting suture of mastectomy dead space compared with conventional closure with drain. Ann Surg Oncol 22:4233-4240

21. Khater A et al (2015) Evaluation of the quilting technique for reduction of postmastectomy seroma: a randomized controlled study. Int J Breast Cancer 2015:287398

22. Mazouni $\mathrm{C}$ et al (2015) Quilting sutures reduce seroma in mastectomy. Clin Breast Cancer 15(4):289-293

23. van Bastelaar $\mathbf{J}$ et al (2016) Flap fixation reduces seroma in patients undergoing mastectomy: a significant implication for clinical practice. World J Surg Oncol 8(14):66

24. Eichler $\mathrm{C}$ et al (2016) Flap adhesion and effect on postoperative complication rates using Tissuglu ${ }^{\circledR}$ in mastectomy patients. Breast Cancer 23:486-490

25. van Bastelaar J et al (2017) Flap fixation using tissue glue or sutures appears to reduce seroma aspiration after mastectomy for breast cancer. Clin Breast Cancer 17(4):316-321
26. Taylor JC et al (2013) Breast cancer surgery without suction drainage: the impact of adopting a 'no drains' policy on symptomatic seroma formation rates. Eur J Surg Oncol 39(4):334-338

27. He XD et al (2011) Whether drainage should be used after surgery for breast cancer? A systematic review of randomized controlled trials. Med Oncol 28(1):9010-9673

28. Divino CM et al (2000) Drains prevent seromas following lumpectomy with axillary dissection. Breast $\mathrm{J}$ 6(1):31-33

29. Somers RG et al (1992) The use of closed suction drainage after lumpectomy and axillary node dissection for breast cancer. Ann Surg 215(2):146-149

30. Zavotsky J et al (1998) Evaluation of axillary lymphadenectomy without axillary drainage for patients undergoing breast-conserving therapy. Ann Surg Oncol 5(3):227-231

31. Cameron AE et al (1988) Suction drainage of the axilla: a prospective randomized trial. Br J Surg 75(12): 1211

32. Sajid MS et al (2013) Fibrin glue instillation under skin flaps to prevent seroma-related morbidity following breast and axillary surgery. Cochrane Database Syst Rev 5:009557 